\title{
Pragmatics Function of Euphemism in Communication
}

\author{
Xianhua Meng \\ Feixian College \\ Linyi University \\ Linyi, China
}

\begin{abstract}
Euphemism is a kind of effective language form used in communication, which aimed to produce reasonable communicative effect. In this paper, the culture features of euphemism are explored. The author also used a lot of effective examples to explain the pragmatic functions of euphemism in communication. In addition, this paper also provides a discussion on how to deal with euphemisms in English teaching, which can harmonious the relationship between teachers and students as well as improve the teaching effects.
\end{abstract}

Keywords-euphemism; pragmatics function; culture features; English teaching

\section{INTRODUCTION}

The word euphemism is derived from a Greek word meaning to speak favorably. Euphemisms are mild, pleasant or inoffensive expressions substituted for harsh, blunt, coarse or unpleasant ones. Euphemism is an important part of language. They are often used out of politeness or consideration for other considers revising. For instance, we would probably say to a friend "I'm sorry to hear your relationship with your brother has not been very smooth." instead of "I'm sorry to hear you often quarrel with your brother." Because we feel that the first statement is more agreeable than the second one. When referring to Marx's death, Engels writes: "He had been left alone for scarcely two minutes, and when we came back we found him in his armchair, peacefully gone to sleep, but for ever." We feel that here, "gone to sleep, but for ever" 15 words are certainly more expressive and appropriate than the blunt and harsh "dead". Then again, when we refer to a friend who has suffering from a brain disease or mental disorder, we would rather use the expression mentally ill than use mad or crazy, because mentally ill is a vague term, which less direct and harsh than mad or crazy.

English euphemism is used very widely, even through the deepest level of human psychological culture. The use of language is determined by the culture in which it exists. Different culture has different euphemisms, in other words, euphemism shows its culture characteristics in communication, and has own pragmatic functions.

\section{CUltural CHARACTERISTIC}

"Language is the principal means whereby we conduct our social lives. When it is used in contexts of communication, it is bound up with culture in multiple and complex ways." To tell more concretely, "language expresses cultural reality" or "language embodies cultural reality" or "language symbolizes cultural reality". These arguments give a profound explanation for the relationship between language and culture. The use of language is determined by the culture in which it exists. Euphemisms are not an exception. In other words, different cultures have different euphemisms.

There are a lot of euphemisms for death both in English and in Chinese. For many Chinese euphemisms of this kind, we can find counterparts in English. For example, to go to sleep, be no more, to abandon the world, to pay the debt of nature, to go to Nirvana... they all have the same meaning of death in English. But in Chinese, there are other euphemisms with no counterparts in English, or more accurately, they refer to the same phenomenon, but differ in cultural implications. The Chinese cultural tradition stresses the importance of hierarchy; the embodiment of hierarchy in language is that different words are adopted for people of different social stratum. It is recorded in The Rites that different social stratums have different expressions for death in ancient China. In English, what word or expression can be used to express the meaning of, for example, death of dukes under an emperor" 薨”? In Webster's Encyclopedic unabridged Dictionary, the example sentence given to "pass away" is: He passed away during the night. From this sentence, we see that in English pass away can refer to anybody's death; while in Chinese, death of dukes under an emperor “薨逝” is confined to the people of the highest rank only.

Different cultural backgrounds make the same thing bring about different psychological images and emotions. For example, "An old white pimp named Tony Roland who was known to handle the best-looking working girls in New York". Obviously, "working girl" is the euphemism for prostitute .But in Chinese, working girl is respected, because they are independent economically. From this point, works in the euphemism composed of color words. These euphemisms are based on protruding signs of colors, which include black as the color of police jackets, green, and the color of the cart for mad men; or on the symbolic meaning of some colors, such as silver for the rich, blue for calmness. Chinese people also have the propensity of using colors as the symbols in some fields, but not as many as English people. Further more, some colors evoke different imaginations in Chinese people from English 
people. For these reasons, euphemisms are masked with cultural color.

Besides, there is a strong tendency to euphemize occupational titles, while in Chinese, it is not so. We may call street sweeper as dustman (person who makes the city more beautiful). But this is mainly seen in formal Chinese, seldom in oral talk. And a janitor will never be called as custodial engineer. In China, people are taught that whatever job they do, they are serving for the people. While in Western countries, different work division are very obvious. A duke would be considered that he demeaned himself if he did manual work with the servants.

The cultural characteristics of euphemisms remind us that a familiarity with the cultural background is essential to the decoding of euphemisms.

\section{PRAGMATIC FUNCTIONS}

Euphemism in English relate to different kinds of social lives. It reflects some principles, which accepted by people in different point of view, such as, conduct principle, social habits, thinking patterns, aesthetic sentiment, value principle and moral principle, etc. According to the pragmatic functions of euphemism in communication, the pragmatic functions of euphemism are used as follow.

\section{A. Replace the Linguistic Taboo}

Restricted by moral standards of the society, some objects or thoughts are not allowed to be referred to straightforwardly. Therefore, they are often used out of politeness or consideration for other people's feelings. People mention them in a fuzzy and euphemistic manner. For example: private parts for vagina/penis have relation with for fuck, have one's periods/ a woman for a week for menstruation, etc. We would probably say to a friend "I'm sorry to hear your relationship with your brother has not been very smooth" instead of "I'm sorry to hear you often quarrel with your brother". Because we feel that the first statement is more agreeable than the second one.

Take death in English for example:

to decease(for legal use)/to go to one's last reckoning

to join the(great)majority/to go the way of all flesh

to Pass away/to go the way of all the earth

to breathe one's last/to go the way of nature

to go west/to go hence

to go to heaven/to go to a better world

to be in heaven/to go out of this world

to yield up the ghost/to go to the better

to expire/to cross the bar(or Bar)

to depart from life/to lose(somebody)

to be taken or called/to be food for fishes

to be gone/to feed the fishes to succumb/to be no more

to kick the bucket(humor slang)/to be close at hand

to come to an untimely end/ to make one's exit

\section{B. Conceal the Essence of Politics or Military Invasion}

Political life, especially the political life in the Western countries, is the gentle land that breeds fuzzy euphemism. For example:

light and scattered action or incomplete success (fussy)/be defeated (precise)

rescue mission or wasting the enemy or pacification (fussy)/invasion(precise)

developing countries (fuzzy)/backward countries (precise)

the disadvantaged/the needy (fuzzy)/the poor (precise)

hot seat (fuzzy)/electric chair (precise)

out of pocked/badly off (fuzzy)/penniless person (precise)

a man in difficulty (fuzzy)/a man in debt (precise)

welfare mother (fuzzy)/jobless mother (precise)

The Watergate scandal in America once drew forth a lot of such fuzzy political euphemism. For example: withholding information was fuzzed as containment; burglar was fuzzed as plumber; the crime of breaking and entering was fuzzed as intelligence gathering activity; cheap flattery was fuzzed as stroking; expensive flattery was fuzzed as puffing; government-sponsored crimes was fuzzed as White House horror...

In western countries, some people avoid using religious words or the name of God, thus people say goodness or goodness gracious instead of saying the word "God". And My Gum is an euphemism of My God. Words like goodness, heaven and gracious are now used in expressions of surprise and annoyance, for example:

My Goodness!/Good Heavens!

Goodness me!/Heaven forbid!

For goodness's sake!/Heaven knows!

Thank goodness!/Gracious!

Goodness knows!/Gracious Heaven!

Goodness knows that!/Gracious me!

By Heaven!/My Gracious!

People also use a certain kind of euphemism to mask realities that ought not to be concealed. For instance, firing means termination of employment; murder means kill with extreme prejudice; bombing means protective reaction strikes. Such attempts trying to cover up the harsh truths are dangerously misleading. In western countries, euphemisms are widely used in advertisements and politics. Advertisers naturally use some delightful or pleasing words to describe their goods in order to expand sales. For instance, an ice-cream 
is described as a skin tonic; a motor car becomes a symphony of speed and style. Politicians try to use vague but delightful expressions to hide harsh facts and exact details. For instance, unemployment department is described as human resources department and concentration camps are named as relocation centers, etc.

\section{Improve the Status of Occupation}

In order to improve the social status or personal reputation, euphemisms are also used to refer to the occupation. For instance, a plant superintendent is really a euphemistic way of speaking for foreman. To some extent, some jobs are considered to be inferior. As a result, many uplifting and fuzzy expressions are adopted to beautify the humble jobs, and the commonly examples are as follows:

undertaker (precise)/funeral service practitioner (fuzzy)

sweat worker (precise)/guest worker (fuzzy)

maid (precise)/domestic help (fuzzy)

housewife (precise)/domestic engineer (fuzzy)

landscape worker (precise)/landscape architect (fuzzy)

butcher (precise)/meat technologist (fuzzy)

secretary (precise)/administrative assistant (fuzzy)

shoe maker(precise)/shoe rebuilder (fuzzy)

garbage man (precise)/sanitation engineer (fuzzy)

dishwasher (precise)/utensil maintenance man (fuzzy)

janitor (precise)/security officer (fuzzy)

ditcher (precise)/excavation technician (fuzzy)

prostitute (precise)/street girl (fuzzy)

\section{Conceal the Essence of Military Invasion}

War is cruel and always refers to blood and death. People who love peace all over the world strongly fight against the war. Euphemism is the best coat in covering the bloody scenes of the war for the politicians and invasion governments. For example:

collateral damage (fuzzy)/civilian casualty (precise)

surgical strike (fuzzy)/surprise attack (precise)

strategically withdrawal (fuzzy)/retreat (precise)

During the US-Viet Nam War, such fuzzy political euphemism is largely used in the American press, for example: " The bombing, burning and imprisonment" is fuzzed as "pacification"; "destroying crops" is fuzzed as "defoliation"; "war" is fuzzed as "conflict"; "aggression" is fuzzed as "police action"; "concentration camp" is fuzzed as "strategically village"; "retreat" is fuzzed as phased "withdrawal"...And during the Iraq War, the "disarm Iraq" and "take military action against Iraq" became the most frequency words in VOA and press. According to Essential English Dictionary, "disarm" means "If you disarm people, you take away their weapons". In addition, "action" means "fighting which takes place in a war". The words such as "disarm" and "take military action" are used instead of "at war" or "attack" achieved certain euphemistic effect.

\section{E. Avoid Vulgarity}

In our daily life, when we refer to something such as sex action, procreation, evacuation or some parts of our body, people prefer to use fussy words instead of direct expression in order to avoid vulgarity.

For example:

- Have sexual intercourse (fuzzy)/make love or sleep together (precise).

- Pregnant (fuzzy)/to be in a delicate condition (precise)/a lady-in waiting(precise); eating for two (precise)/have one on the way (precise);an expectant mother (precise)...

Lavatory is the formal expression in daily life. Ladies' room or men' room are usually used instead of using lavatory. Ladies room is even more elegant. Dressing room, power room, lounge, washroom are also more graceful than lavatory.

There are also kinds of expressions for "go to WC", we can say:

May I please be excused?

May I please leave the room?

I'm going to do my business.

I'm going to my private office.

May I use the facilities?

What's the geography of the room?

The Menstruation in English is often used as follows:

My friend has come.

I have the flowers.

She is riding the cotton bicycle.

She is flashing the red flag.

She has her period.

The red sea is in.

\section{F. Avoid Discrimination}

In order to avoid prejudice or sympathy by others, there are a lot of words or expression of euphemisms from the ancient times to nowadays.

Let's take poor for example. We can use the following words or expressions to show poor:

needy/underprivileged/the indigent/broke/stone broke/flat broke down and out/ haven't a bean live from hand to mouth/badly off down on one's luck/the low-income/the underprivileged/the economically deprived 
And ghetto/slum area can express as inner city or substandard housing. Even poor country can be called underdeveloped country or developing country.

\section{DISCUSSIONS ON EUPHEMISMS AND ENGLISH TEACHING}

Euphemisms are a linguistic technique for people to achieve various goals in communication. Therefore, encoding euphemisms correctly and using them properly are closely related to whether an individual can conduct successful communication, which is the final aim of English teaching- to help the students communicate with native English speakers successfully. In English teaching, should we encourage the students to use euphemisms in their talk and writing? The euphemisms reflect people's values and morals. How can we help students find out the nature of the people who speak one language as their mother tongues through euphemisms? Different cultures bring about different euphemisms. Can we help the students understand English culture through euphemisms? Nowadays when people tend to use more and more euphemisms, these questions should be taken into serious consideration in English teaching.

In order to solve the problems above, teachers should pay attention to the following points. Firstly, the importance of euphemisms in communication should be made clear to students. During English teaching, for the euphemisms, which are used at a higher frequency in daily communication, teachers should present a brief introduction about their cultural background and the context in which these euphemisms are used so that students can use them properly. Secondly, just as what is mentioned in the part of Social Functions of Euphemisms, "different languages can lead people to different actions." Teachers should encourage students use some euphemisms in their communication. By doing so, the communication can go more smoothly, and in addition, through using euphemisms, students can develop elegant interests and their quality can be enhanced. In brief, for the sake of the social functions and unique cultural color, euphemisms should occupy an important position in English teaching and learning. Enough attention should be paid.

Evaluating the students, the teacher should use some fuzzy and euphemistic expressions and avoid the direct and offensive words in case that the students' self-esteem be injured, for example:

- "I am sorry to find him an underachiever for some major courses" for "He has failed some major courses".

- "He is sure to go far if he can use his resources fully" for "The student is lazy".

- "He depends on others to do his work" for "He cheats".

- "He sometimes takes others' things without permission." for "He sometimes steals others' things".

- "He teaches the special students." for "He teaches the disabled students".

\section{CONCLUSION}

To sum up, the pragmatic function of euphemism is not to be ignored. It can express of meaning tactfully and politely without making others feel embarrassed, as the direct statement sometimes does. Euphemism, which is also called cosmetic words, is permeated with politics, economy, culture, etc. Euphemism is widely used because it is related to all walks of life, covering birth, age, illness and death. As a result of all these euphemism has great vitality. It is my sincere hope that this paper will contribute to further research on euphemisms as well as to pragmatic studies of fussy euphemism and English teaching. Just as Enrigh, D.J. said in his book Fair of Speech - The uses of Euphemism: "If without euphemism, the whole world will full of recentness."

\section{REFERENCES}

[1] Liangxiang Dong. How to Improve English Teaching Effect, [J] Education Innovation, 2007, (5).

[2] The Develop [3] Liangxiang Dong. How to Improve English Teaching Effect, [J] Education Innovation, 2007, (5).

[3] The Development of Language Sense in College English Teaching [J] Higher Education Research, 2014, (10).

[4] Saeed , J. I. Semantics[M].Beijing: Foreign Language Teaching sand Research Press .2000.

[5] Marriam Webster's Collegiate Dictionary [M] .New York:Marriam? Webster.2000.

[6] Cheng Musheng. Handouts for General Linguistics [M].2001

[7] Kramsch, C. Language and Culture [M]. Shanghai: Foreign Languge Education Press.2000. 